\title{
Phenotypic and phylogenetic characterization of acetogenic sporulated cocci isolated from the rumen
}

\author{
F Rieu-Lesme 1, C Dauga 2, B Morvan 1, G Fonty 1, J Doré 3 \\ 1 INRA, Laboratoire de Microbiologie, C.R. de Clermont-Ferrand-Theix, 63122 Saint-Genès-Champanelle, \\ 2 Institut Pasteur, Unité des Entérobactéries, 28 rue du Docteur Roux, 75724 Paris Cédex 15, \\ 3 INRA, Laboratoire de Nutrition et Sécurité Alimentaire, Domaine de Vivert, 78352 Jouy-en-Josas Cédex, \\ France
}

Anaerobic $\mathrm{H}_{2}$-utilizing acetogenic bacteria are present in numerous ecosystems such as sediments, sludge, intestinal tracts of animals. They use $\mathrm{H}_{2}+\mathrm{CO}_{2}$ as energy source catalyzing a total synthesis of acetate from this gas mixture. One of the objectives in manipulating rumen fermentation is to replace methanogenesis, which represents a loss of energy for the ruminant and a source of pollution to the atmosphere, by acetogenesis as an $\mathrm{H}_{2}$-utilizing pathway. The current knowledge of the diversity of acetogenic rumen bacteria is still very poor. In a previous study we have shown that acetogenesis is important in new born lambs before establishment of methanogenic archaea and some representative strains of this group have been isolated (Morvan et al, 1994, FEMS Microbiol Lett, 117, 249-256; Rieu-Lesme et al, 1995, FEMS Microbiol Lett, 125, 77-82)

Acetogens were isolated under $\mathrm{H}_{2}: \mathrm{CO}_{2}$ by direct plating on $\mathrm{AC} 11$ medium with $20 \mathrm{~g} / \mathrm{lagar}$ using the roll-tube technique. The present investigation revealed that the predominant acetogens in the rumen of lambs, llamas and bisons are cocci occuring in long chains forming endospores. Our isolates (thirteen) were the first Gram positive spore-forming cocci recognized as acetogenic. All isolates show high phenotypic similarities, they are non motile, electron microscopy observations show a typical trilaminar structure of the cell wall, with an electron-dense extracellular material over the entire cell surface. All isolates are able to grow heterotrophically with numerous organic substrates including glucose, cellobiose glycerol. Acetate is the major end product from glucose. Two isolates are able to $\mathrm{O}$-demethylate aromatic compounds. Yeast extract is required to use $\mathrm{H}_{2}+\mathrm{CO}_{2}$ and autotrophic acetate production was proportionnal to the concentration of yeast extract in the medium. One of these isolates was characterized in details and a total of 1316 nucleotides of the $16 \mathrm{~S}$ rRNA were sequenced. For this strain optimum conditions for growth under $\mathrm{H}_{2}+\mathrm{CO}_{2}$ were $37^{\circ}-40^{\circ} \mathrm{C}$ and $\mathrm{pH}$ (initial) $6,3-6,8$. Under these conditions the amount of acetate formed reached $80 \mathrm{mM}$. The $\mathrm{G}+\mathrm{C}$ ratio of the DNA was $46,5 \mathrm{~mol} \%$. The $16 \mathrm{~S}$ rRNA sequence analysis shows that the isolate was a new genomic species closely related to Ruminococcus (P) hansenii, Clostridium coccoides and Ruminococcus $(\mathrm{P})$ productus, but the degree of 16S rRNA sequence similarity with the nearest species was significantly low (78\%). We have recently shown that these three species were also able to use $\mathrm{H}_{2}+\mathrm{CO}_{2}$. Our data are in full agreement with the necessity for a major revision of "Clostridium and relatives" assemblage. The study of diversity of all our isolates on the basis of DNA-DNA hybridization and further work on their physiology will lead to a better understanding of the functional role of this important group of bacteria in the ruminal microbial community. 